УДК 621.74

О.Г. Чернета, к.т.н., доцент

В.І. Сухомлин, к.т.н., доцент

Р.Г. Волощук, аспірант

Дніпровський державний технічний університет, м. Кам'янське

\title{
МАТЕМАТИЧНЕ МОДЕЛЮВАННЯ СТУПЕНІ ЗНОСУ ПОВЕРХНЕВОГО ШАРУ ДЕТАЛЕЙ В ЗАЛЕЖНОСТІ ВІД РЕЖИМІВ НАВАНТАЖЕННЯ
}

В роботі розглянуті методи отримання зносостійких покриттів і проведено математичне моделювання ступені зносу поверхневого шару в залежності від режимів комбінованих навантажень. Отримані графічні залежності інтенсивності зносу поверхневого шару деталі в залежності від твердості, швидкості, режимів комбінованих навантажень і терміну трибологічних іспитів.

Проведений аналіз трансформачії структури зносостійких шарів з сталі 45 в залежності від технологічних методів і фізико-механічних властивостей робочих поверхнею, щзо наведені на фотографіях з мікроструктурами відповідних шарів робочих поверхнею. Також наведені графічні залежності мікротвердості відповідних зон робочих поверхонь.

Ключеві слова: математичне моделювання, мікротвердість, мікроструктура.

Methods of obtaining wear-resistant coatings are considered in this work, and mathematical modeling of the degree of wear of a surface layer is carried out, depending on the modes of combined loads. The graphic dependences of the intensity of wear on the surface layer of the component are obtained depending on the hardness, speed, combined loading modes and the period of tribological exams.

An analysis of the transformation of the structure of wear-resistant layers from steel 45 is carried out depending on the technological methods and physical and mechanical properties of the working surfaces, which are given in photographs with microstructures of the corresponding layers of the working surface. Also graphic dependences of microhardness of the corresponding areas of working surfaces are given.

Keywords: mathematical modeling, microhardness, microstructure.

\section{Постановка проблеми}

Пріоритетним напрямом вибору зносостійких покриттів в машинобудуванні є оптимальний вибір технологічних способів обробки і нанесення покриттів 3 високими фізикомеханічними, міцними і експлуатаційними властивостями. Критерієм оцінки зносостійкості покриттів $є$ довговічність і ресурс роботи контактуючих пар тертя. Від правильного вибору зміцнення поверхневого шару деталей машин залежить ефективність кінцевого результату ресурс роботи механізму. Але натурні, трибологічні іспити - процес доволі довгий і витратний. Запропонована модель 3 використанням ортогонального центрального композиційного плану другого порядку дозволяє з високим ступенем імовірності, де можливо задавати ідентичні параметри реальних навантажень і одержати математичну залежність по визначенню зносостійкості тестуємих покриттів і структур.

\section{Аналіз останніх джерел досліджень і публікацій}

Відомо безліч методів зміцнення поверхні сталей [1-6] та традиційні методи дослідження зносостійкості на машинах тертя. Але в реальних умовах експлуатації виникає маса неврахованих параметрів, які не дозволяють в повній мері моделювати процеси, що протікають у вузлах механізмів з інтенсивними, знакозмінними навантаженнями $[7,8]$. Тому виникає необхідність для кожного конкретного випадку взаємодії трибологічних пар розробка оригінальної моделі з заданими параметрами і реальними навантаженнями при іспиті на зносостійкість.

\section{Мета роботи}

Ціллю роботи є моделювання процесів тертя в контактуючих трибологічних парах 3 отриманням математичної залежності інтенсивності зносу поверхневого шару деталі при різних режимах комбінованих навантажень. 


\section{Надання основного матеріалу}

На рис.1 представлена графічна модель залежності твердості поверхневого шару деталі 3 сталі 45 від технологічних зміцнюючих способів обробки [1]. На графічній моделі можно наочно спостерігати динаміку і трансформацію мікроструктури від якої залежать фізикомеханічні властивості робочої поверхні деталі з сталі 45.

НВ МПа

12000

8000

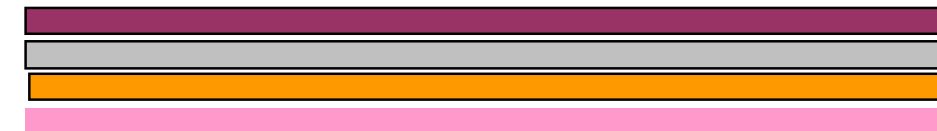

6000
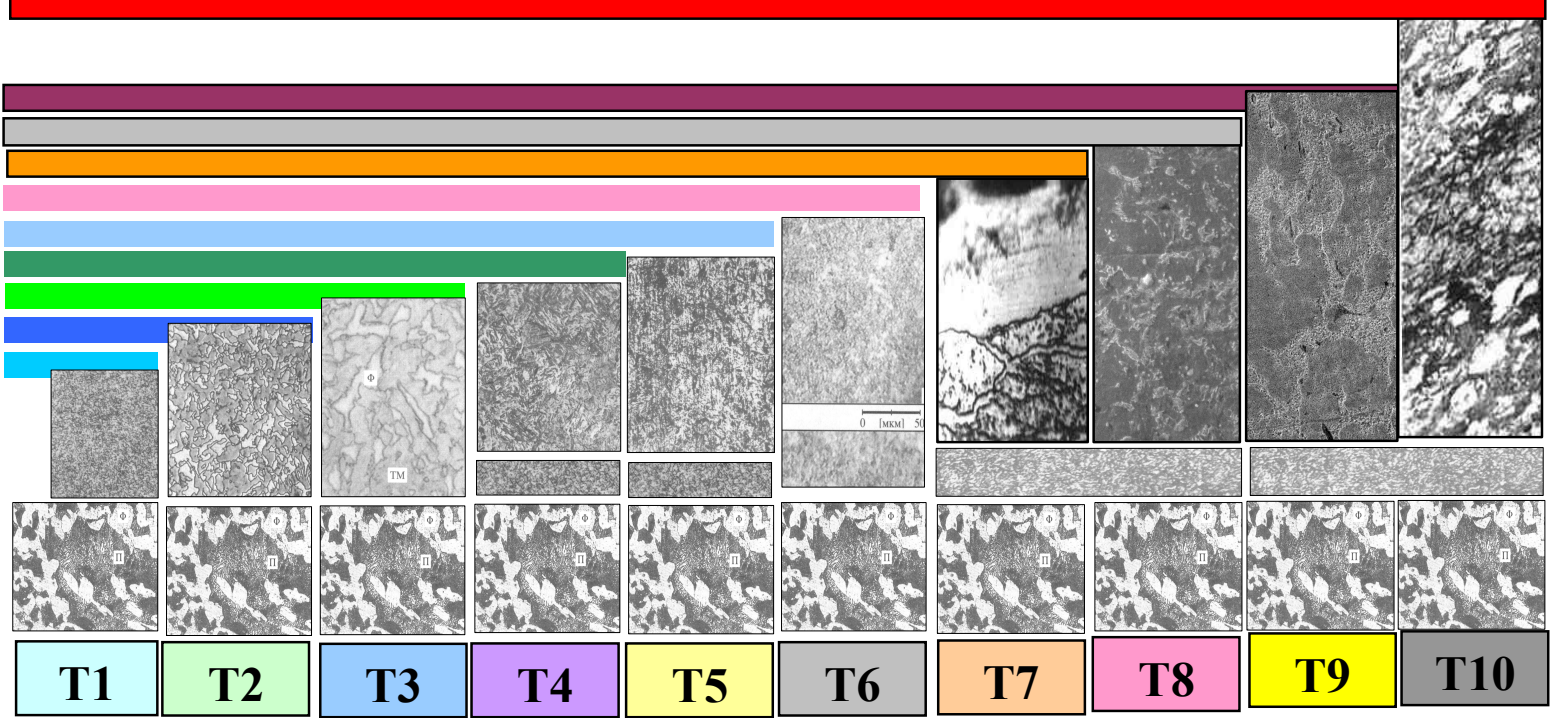

(Т1 - сорбітизація; Т2 - гарт 3 охолодженням в маслі - тростит і ферит; Т3 - гарт 3 охолодженням у воді - тростомартенсит и феріт; Т4 - гарт 3 з охолодженням в маслі — тростомартенсит; Т5 - гарт 33 охолодженням у воді - гольчастий мартенсит; Т6 - СВЧ - безструктурний мартенсит; Т7 - після азотування - високо азотисті фази - нітриди $-\mathrm{Fe}_{3} \mathrm{~N}, \mathrm{Fe}_{4} \mathrm{~N}$; Т8 - борування $з$ утворенням боридів; Т9 - гарт СВЧ - мартенсит; Т10 - азотування 3 наступною лазерною обробки - гарденіт [9] з зонами карбонітридів типу $\mathrm{Me}_{7}(\mathrm{CN})_{3}$ і нітридів типу $\mathrm{Fe}_{3} \mathrm{~N}$

Рис. 1. Графічна модель залежності твердості поверхневого шару з сталі 45 від технологічних зміцнюючих способів обробки

Отримати точну математичну залежність для визначення ступені зносу $I_{h}$ від впливу експлуатаційних параметрів можливо за допомогою методу планування експерименту [10], 3 використанням ортогонального центрального композиційного плану другого порядку.

В більшості фізичних експериментів загальний характер розподілу випадкових величин можливо представити на основі попередніх вимірювань. Достеменність оцінки середнього генерального скупчення можливо описати за допомогою квантилів нормувального нормального розподілу [2]. В експерименті досліджується $\Delta m$ - втрата маси матеріалу в процесі зносу (X). На процес зносу впливає мікротвердість $H_{\mu 50}$ матеріалу покриття $\left(\mathrm{X}_{1}\right)$, контактний тиск $P\left(\mathrm{X}_{2}\right)$, швидкість руху зразка $V\left(\mathrm{X}_{3}\right)$ і час процесу зносу $\tau\left(\mathrm{X}_{4}\right)$. Експериментальні дослідження проводились за допомогою лабораторної трибологічної машини тертя з почасовою фіксацією втрати маси зразків. Рівні варіювання факторів, що впливають на ступінь зносу зразків, наведені в таблиці 1. Матриця планування і результати повнофакторного експерименту з урахуванням параметрів $H_{\mu 50}=3600 . .9300 \mathrm{MПа,} P=30 . .50 \mathrm{H}, V=2.4 . .3 \mathrm{~m} / \mathrm{c}, \tau=1 . .3$ часу надані в табл. 2. В результаті обробки даних експерименту були отримані оцінки впливу факторів, їх квадратів $\mathrm{i}$ взаємодії меж собою на величину $\Delta m$. 
Таблиия 1. Фактори і рівні їх варіювання в експерименті для 4x параметрів

\begin{tabular}{|l|c|c|l|l|l|l|}
\hline \multicolumn{1}{|c|}{ Фактори } & $\begin{array}{c}\text { Позначення } \\
\text { факторів }\end{array}$ & $\bar{x}_{i}=-1.414$ & $\bar{x}_{i}=-1$ & $\bar{x}_{i}=0$ & $\bar{x}_{i}=1$ & $\bar{x}_{i}=1.414$ \\
\hline Мікротвердість, $H_{\mu 50}$, МПа & $\mathrm{X}_{1}$ & 2420 & 3600 & 6450 & 9300 & 10479.9 \\
\hline Контактний тиск, $P, \mathrm{H}$. & $\mathrm{X}_{2}$ & 25.86 & 30 & 40 & 50 & 54.14 \\
\hline Швидкість руху, $V, \mathrm{~m} / \mathrm{c}$ & $\mathrm{X}_{3}$ & 2.28 & 2.4 & 2.7 & 3.0 & 3.12 \\
\hline Час $\tau$, год & $\mathrm{X}_{4}$ & 0.586 & 1.0 & 2.0 & 3.0 & 4.414 \\
\hline
\end{tabular}

Таблица 2. Матриця планування і результати повнофакторного експерименту

\begin{tabular}{|c|c|c|c|c|c|}
\hline № & $H_{\mu 50}, \mathrm{M \Pi а} \mathrm{X}_{1}$ & $P, \mathrm{H} . \mathrm{X}_{2}$ & $V, \mathrm{~m} / \mathrm{c} \mathrm{X}_{3}$ & $\tau$, час $\mathrm{X}_{4}$ & $\Delta m, г \mathrm{p}$ \\
\hline 1 & $3600-$ & $30-$ & $2.4-$ & $1-$ & 0.026 \\
\hline 2 & $3600-$ & $30-$ & $2.4-$ & $3+$ & 0.076 \\
\hline 3 & $3600-$ & $30-$ & $3.0+$ & $1-$ & 0.028 \\
\hline 4 & $3600-$ & $30-$ & $3.0+$ & $3+$ & 0.078 \\
\hline 5 & $3600-$ & $50+$ & $2.4-$ & $1-$ & 0.027 \\
\hline 6 & $3600-$ & $50+$ & $2.4-$ & $3+$ & 0.127 \\
\hline 7 & $3600-$ & $50+$ & $3.0+$ & $1-$ & 0.043 \\
\hline 8 & $3600-$ & $50+$ & $3.0+$ & $3+$ & 0.136 \\
\hline 9 & $9300+$ & $30-$ & $2.4-$ & $1-$ & 0.005 \\
\hline 10 & $9300+$ & $30-$ & $2.4-$ & $3+$ & 0.016 \\
\hline 11 & $9300+$ & $30-$ & $3.0+$ & $1-$ & 0.006 \\
\hline 12 & $9300+$ & $30-$ & $3.0+$ & $3+$ & 0.017 \\
\hline 13 & $9300+$ & $50+$ & $2.4-$ & $1-$ & 0.008 \\
\hline 14 & $9300+$ & $50+$ & $2.4-$ & $3+$ & 0.024 \\
\hline 15 & $9300+$ & $50+$ & $3.0+$ & $1-$ & 0.008 \\
\hline 16 & $9300+$ & $50+$ & $3.0+$ & $3+$ & 0.025 \\
\hline 17 & 64500 & 400 & 2.70 & 20 & 0.018 \\
\hline 18 & 64500 & 400 & 2.70 & 20 & 0.018 \\
\hline 19 & 64500 & 400 & 2.70 & 20 & 0.018 \\
\hline 20 & 64500 & 400 & 2.70 & 20 & 0.018 \\
\hline
\end{tabular}

В результаті перевірки результатів експерименту знайдена дисперсія помилок спостережень $S=1$ при ступені вільності $f=2$.

Перевірені значущості коефіцієнтів регресії за критерієм Стьюдента для рівня $q=0.05$ і ступеня вільності $f=2$ і показана значимість факторів $\overline{x_{1}}, \overline{x_{2}}, \overline{x_{3}}, \overline{x_{4}}$, а також їх взаємодіi $\overline{x_{1}} \overline{x_{2}}, \overline{x_{1}} \overline{x_{3}}, \overline{x_{1}} \overline{x_{4}}, \overline{x_{2}} \overline{x_{3}}, \overline{x_{2}} \overline{x_{4}}, \overline{x_{3}} \overline{x_{4}}$.

В результаті отримана функція відгуку:

$$
\begin{aligned}
& y=-3.752-0.777 \overline{x_{1}}+0.196 \overline{x_{2}}+0.054 \overline{x_{3}}+0.585 \overline{x_{4}}-0.0025 \overline{x_{1}} \overline{x_{2}}-0.019 \overline{x_{1}} \overline{x_{3}}- \\
& -0.03 \overline{x_{1}} \overline{x_{4}}+0.02 \overline{x_{2}} \overline{x_{3}}+0.038 \overline{x_{2}} \overline{x_{4}}-0.032 \overline{x_{3}} \overline{x_{4}} \text {. } \\
& \text { При цьому } \overline{x_{1}}=\frac{2\left(\ln H_{\mu 50}-9.138\right)}{9.138-8.102}+1 ; \quad \overline{x_{2}}=\frac{2(\ln P-3.912)}{3.912-3.4}+1 ; \quad \overline{x_{3}}=\frac{2(\ln V-1.099)}{1.099-0.875}+1 ; \\
& \overline{x_{4}}=\frac{2(\ln \tau-1.099)}{1.099}+1 \text {. }
\end{aligned}
$$

Перевірка адекватності спостерігаємих значень величини $y=\Delta m$ показала, що розрахункові значення критерію Фішера $F_{\mathrm{p}}=15.27$, (табличне значення $F_{\mathrm{r}}=19.42$ ). 
Таким чином, отримана математична модель, що адекватна реально існуючий і досліджуємій моделі. Для вправності проведення розрахунків кодовані перемінні замінюються відповідними фізичними величинами:

$$
\begin{aligned}
& \Delta m=5.1-1.151 \ln H_{\mu 50}+1.584 \ln \tau+1.313 \ln V+0.111 \ln P-0.357 \ln H_{\mu 50} \ln V- \\
& -0.115 \ln H_{\mu 50} \ln \tau+0.696 \ln P \ln V+0.271 \ln P \ln \tau-0.518 \ln \tau \ln V-0.02 \ln H_{\mu 50} \ln P .
\end{aligned}
$$

Отримана формула (2) враховує вплив багатофакторної системи трибологічної взаємодії контактуючих поверхонь і дозволяе розрахунковим шляхом за заданими параметрами $\left(H_{\mu 50}, P, V, \tau\right)$ з високою достеменністю прогнозувати ступінь зносостійкості покриттів з різними видами зміцнення.

Дослідження ефективних матеріалів покриттів в реальних умовах виробництва доволі складний, витратний і тривалий процес. Для прискореної оцінки зносостійкості покриттів була створена лабораторна трибологічна машина.

Але для відтворення умов навантаження пар тертя в трибологічній машині, що адекватні роботі в двигуні внутрішнього згорання, необхідно знати величину зосередженої сили $P$, що діє в торцевому перетині дослідного зразка, яку можна визначити з виразу (2), підставивши в нього величину контактного тиску $q$ з формули (3):

$$
P=\frac{E \cdot I \cdot \Delta \cdot \sin \alpha}{r^{3}[3 \cdot \sin \alpha+(\pi-\alpha)(2+\cos \alpha)]} .
$$

Підставивши величину $P$ в математичну залежність (3) одержимо формулу для визначення масового зносу поверхневого шару деталі з урахуванням реальних контактних навантажень і напружень, що виникають в парах тертя:

$$
\begin{aligned}
& \Delta m=5.1-1.151 \ln H_{\mu 50}+1.584 \ln \tau+1.313 \ln V+0.111 \ln \frac{E \cdot I \cdot \Delta \cdot \sin \alpha}{r^{3}[3 \sin \alpha+(\pi-\alpha)(2+\cos \alpha)]}- \\
& -0.357 \ln H_{\mu 50} \ln V-0.115 \ln H_{\mu 50} \ln \tau+0.696 \ln \frac{E \cdot I \cdot \Delta \cdot \sin \alpha}{r^{3}[3 \sin \alpha+(\pi-\alpha)(2+\cos \alpha)]} \ln V+ \\
& \quad+0.271 \ln P \ln \tau-0.518 \ln \tau \ln V-0.02 \ln H_{\mu 50} \ln \frac{E \cdot I \cdot \Delta \cdot \sin \alpha}{r^{3}[3 \sin \alpha+(\pi-\alpha)(2+\cos \alpha)]} .
\end{aligned}
$$

Розрахунки ступені зносу поверхонь тертя, що виконані з урахуванням впливу чотирьох факторної системи $(H, P, V, \tau)$ згідно залежності (4) і за допомогою комп'ютерної програми «Mad Cad 2000», дозволили одержати розрахункові данні по визначенню ступені зносу досліджуємих зразків.

Крім того отримані графічні залежності ступеня зносу зразків від фізико-механічних властивостей покриттів $\Delta m\left(H_{\mu}\right)$, умов навантаження $\Delta P(H), \Delta V(H)$ і часу навантаження $\Delta m(\tau)$. Залежність $\Delta m\left(H_{\mu}\right)$ описується гістограмою, що при твердості покриття $H_{\mu 50}=3000$ МПа має максимальну ступень зносу і рівну 0.08 гр.

У міру збільшення твердості ступінь зносу зразків зменшується, а при іiї максимальному значенні $H_{\mu 50}=3000$ МПа значення $\Delta m=0.01$ гр.

Аналогічні залежності відтворені на графіках $\Delta m=f(P), \Delta m=f(V), \Delta m=f(\tau)$ (рис. $2 a, \sigma$, $3 a$, б) $з$ яких витікає, що при максимальних значеннях тиску, швидкості і тривалості навантажень ступень зносу досліджуємих зразків максимальна, а при їх мінімальних значеннях ступінь зносу є мінімальною. Аналіз кривих ступеня зносу, що отримані за розрахунковими значеннями даних при $V=2.4 \mathrm{~m} / \mathrm{c}, P=30 \mathrm{H}$ и (рис. 2) при $V=3 \mathrm{~m} / \mathrm{c}, P=50 \mathrm{H}$ свідчить про високу зносостійкість азотованого зразка з наступною лазерною обробкою. Втрата маси цих зразків при трьохгодинному циклі іспитів на трибологічній машині нижче, ніж у покриттів 3 нітридів цирконію і нітридів титану в $5 . .7$ разів, що свідчить про високі експлуатаційні властивості покриттів з структурою в поверхневому шарі гарденіту з мікротвердістю $H_{\mu 50}=7000 \ldots 9300$ МПа. 


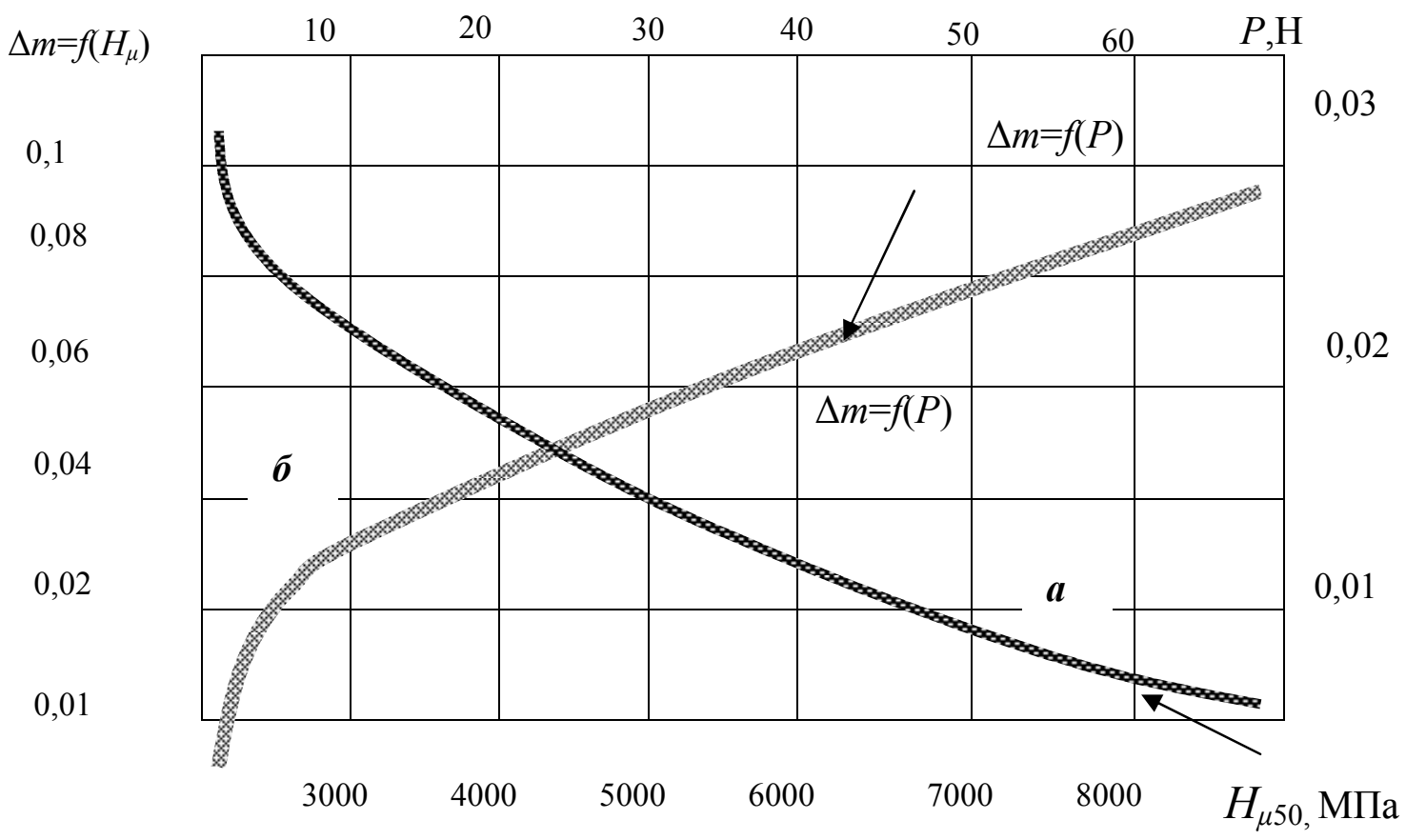

Puc. 2. Залежність ступені зносу от $a-$ мікротвердості і $\sigma-$ контактного тиску

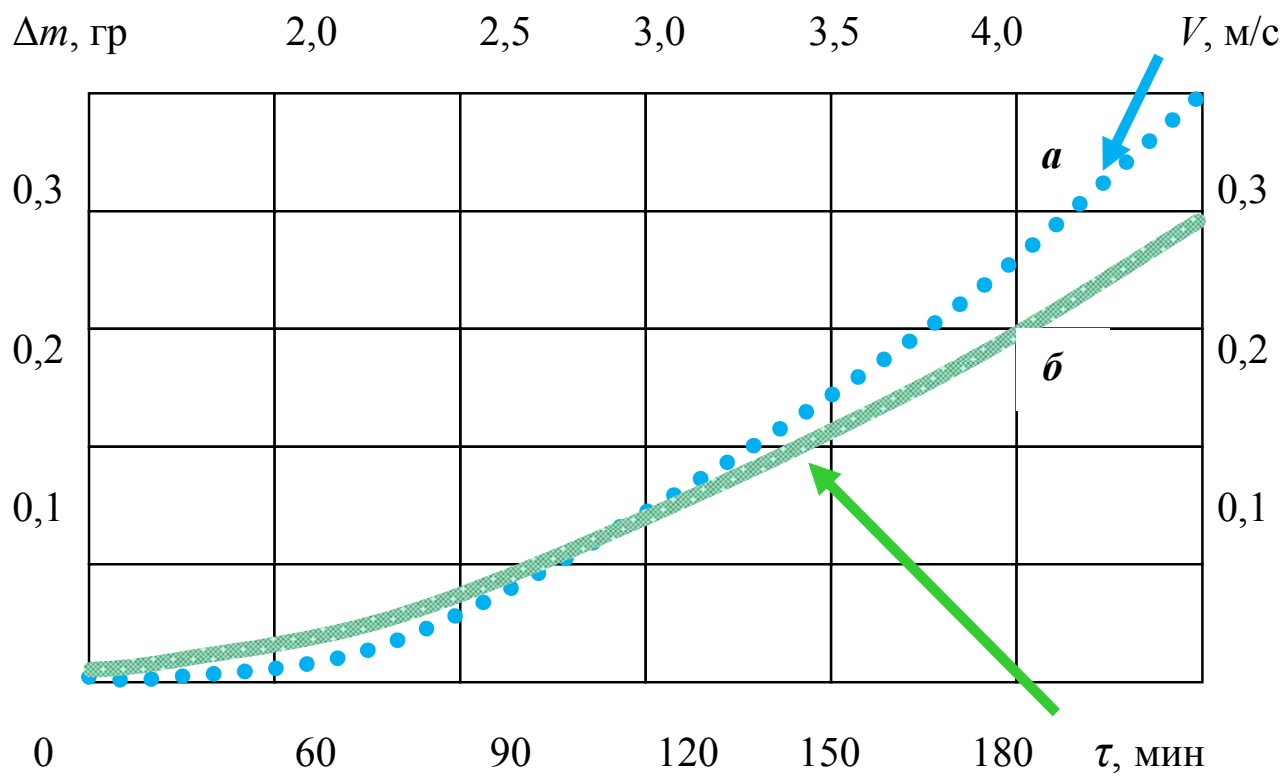

Рuc. 3. Залежністі ступеня зносу від $a$ - швидкості переміщення контрзразка і $\sigma$ - тривалості трибологічних випробувань

Для побудови графіків $\Delta m=f(P), \Delta m=f(V), \Delta m=f(\tau)$ (рис. 2,3$)$ використовувалися розрахункові данні покриттів 3 максимальними фізико-механічними характеристиками $H_{\mu 50}=9300$ МПа і максимальними режимами навантаження $(P=50 \mathrm{H}, V=3$ м/сек, $)$. При збільшенні контактних навантажень, швидкісних режимів і циклів іспитів ступінь зносу зразків суттєво підвищується, що свідчить про влив кожного окремо взятого фактору на загальну картину зносу поверхні тертя. 
При порівнянні графіків ступеня зносу досліджуємих зразків, що отримані на основі розрахункових даних при плануванні багатофакторного експерименту і експериментальних даних трибологічних досліджень простежується подібність характеру зносу різних покриттів, що доказує можливість використання даної математичної моделі до вибору матеріалів і покриттів, прогнозування з більшою достеменністю ступеня зносостійкості і терміну напрацювання даного матеріалу або покриття.

\section{Висновки}

Проведений аналіз існуючих технологічних способів зміцнення поверхневого шару деталі. Досліджена динаміка трансформації мікроструктур при реалізації ряду технологічних способів зміцнення. Розроблена графічна модель залежності твердості поверхнево шару сталі 45 від зміцнюючої технології обробки. Отримана математична модель з використанням ортогонального центрального композиційного плану другого порядку, що дозволяє с високою ступеню достеменності при заданих ідентичних параметрах реальних навантажень, отримати математичну залежність по визначенню зносостійкості деталей.

\section{Список використаної літератури}

1. Аналіз трансформацій мікроструктури поверхневого шару із сталі 45 в залежності від технологічних методів обробки. О.Г. Чернета, В.І. Сухомлін, О.М. Коробочка // ЗНП "Перспективні технології та прилади/Луцький НТУ, № 11(2)2017. - С. 147-152.

2. Середа Б.П. Поверхневе зміцнення матеріалів. Монографія /Середа Б.П., Калініна Н.С., Кругляк І.В. - Запоріжжя. РВВ ЗДІА, - 2004, - 230 с.

3. Скорняков Є.С., Чернета О.Г., Волощук Р.Г. Відновлення кулачків розподільних валів електродуговою наплавкою.ЗНП ЛНТУ № 7(2)2015, - 113 с.

4. Аналіз механізмів зміцнення середнє вуглецевих сталей. О.Г. Чернета, В.І. Кубіч, Е.С. Скорняков // ЗНП "Перспективні технології та прилади/Луцький НТУ, № 11(2)2017. - С. 142146.

5. Surface modification and alloying by laser, ion, and electron beams /J.M. Poate, G. Foti, D.C.Jacobson / M. Машиностроение 1987 - C. 301.

6. Hu W.W., Herman H., Clayton C.R. et.aI. ln: Ion Implatation Metallurgy / ed. G.M.Preece and J.K. Hirvonen. New York: TSM-AIME, 1980.

7. Marvick A.D. Nucl. Instr. Methods. 1981. vol. 182/183, p. 827.

8. Mantl S., Sharma B.D., Antesberger G. Phil. Mag. 1979. vol. 39A, p. 389.

9. Зав'ялов А.С., Теплухін Г.Н., Габеев К.В. Условия и механізм образования безструктурного мартенсита (гарденита). Металловедение и термическая обработка метал лов. № 10 - 1979. C. $11-12$.

10. Гришкин В.К. Статистические методы анализа и планирования эксперимента. Разработки Московского университета / 1975 - 41 С. 